\title{
An intersectional approach to Men's Health
}

\section{Keywords \\ Social \\ determinants \\ Men's health \\ disparities \\ Intersectional \\ Intersectionality}

Derek M. Griffith, PhD University of Michigan, School of Public Health, 1415 Washington Heights, Ann Arbor, Michigan 48109-2029, USA

E-mail:

derekmg@umich.edu

Online 21 April 2012

\section{Derek M. Griffith}

\begin{abstract}
Men's lives and health are rooted in opportunity structures that are shaped by race, ethnicity and other characteristics that have important social, political, economic and cultural meaning. Within men's health, there is a need to consider how structural factors and men's socially-defined characteristics affect the relationship between sex, gender and health. The goal of an intersectional approach is to simultaneously examine the social and health effects of several key aspects of identity and context in ways that create a new understanding of these factors and that are a more accurate reflection of the lived experiences of the populations of interest. Despite their promise, intersectional approaches have been criticized for being difficult to operationalize and study systematically. This paper, however, presents a framework for studying the intersection of gender and other identities and characteristics that are relevant for men's health, and explicitly identifies key pathways and stratification variables to guide future research.

This framework highlights pathways and ways to think about why race, gender, age and ethnicity affect men's health, and offers a tool for studying the relationship between socially-defined characteristics and men's health. Future research on men's health should begin by recognizing that comparing how men experience and embody masculinities may be most useful when researchers are explicit about their assumptions and theories about what and how socially-defined characteristics intersect with gender in a given national and local context. Research employing an intersectional approach also may elucidate how men of specific population groups create new normative masculinities for themselves. ๑ $2012 \mathrm{WPMH}$ $\mathrm{GmbH}$. Published by Elsevier Ireland Ltd.
\end{abstract}

Men's health is based on understanding the social and health implications of gender, a socially-defined construct, but it is critical to consider that gender depends on other social categories for meaning [1]. Analyses that focus on gender without consideration of other identities and group memberships implicitly assume other social statuses that go unnamed: race, ethnicity, heterosexuality, social class, economic status, ability status and others [1-3]. Intersectionality is an analytic and theoretical approach that considers the meaning and consequences of socially-defined constructs and that offers new ways of understanding the complex causality of social phenomena [1]; thus, it is a useful framework for examining the complexity of men's health and men's health disparities [4].

The goal of an intersectional approach is to simultaneously examine the social and health effects of key aspects of identity and context [4-6]. Health researchers tend to consider these characteristics separately in an effort to identify their independent and additive effects, but these characteristics jointly and simultaneously structure health practices and health outcomes [7]. An intersectional approach suggests that socially-defined and socially meaningful characteristics are inextricably intertwined and experienced simultaneously. Thus, intersectional approaches help men's health researchers to examine how the blending of identities and experiences create a new understanding of these factors, and arguably a more accurate reflection of the determinants of men's health.

While there is considerable support for intersectional approaches, there also have been a number of methodological critiques $[8,9]$. Researchers have found intersectional approaches useful conceptually as a way to examine the complex array of factors that affect the health of women of color, but it 
has been unclear how intersectional approaches can be maximized to examine diversity among men or compare women and men. Also, intersectional approaches have been criticized for rendering some identities invisible in efforts to highlight others [9]. This type of intersectional invisibility [10] has occurred when researchers were not clear about their assumptions and hypotheses regarding why key social determinants of health and socially-defined characteristics are relevant to health. While it has become more sophisticated in exploring the meaning of gender in men's lives, men's health research could benefit from moving beyond thinking about the ways that gendered social and cultural factors influence health to identifying modifiable mechanisms and pathways that connect gender and men's health.

\section{Why intersectionality in men's health?}

Intersectionality is an approach that seeks to help researchers become more deliberate, thoughtful and explicit about why they choose particular variables, characteristics, identities, and intersections to include in studies [9]. In men's health literature, issues of race, ethnicity, sexual identity and orientation, disability status and geography are critical determinants of men's health yet they are rarely integrated into study designs and analyses of men's identities, health practices and health outcomes $[3,11]$. Ethnicity, economic status, educational attainment, sexual orientation, and social context are important factors that influence the type of masculinity that men construct, and have implications for the differential health risk among different types of men [12-15].

Within the field of Men's Health, men's health disparities is a sub-area that considers how the health of men is determined by cultural, environmental and economic factors associated with socially-defined identities and group memberships [3]. Approaching men's health with focused attention on men's health disparities highlights gendered pathways that increase men's risk of developing or dying from certain conditions and illnesses and helps to identify positive aspects of masculinity by considering how men marshal social and cultural resources to mitigate racism, ethnic oppression, and other forces that may adversely affect their health [16-18]. Focusing on men's health disparities enables a research agenda that examines (1) how masculinities are related to health [13,19-21]; (2) how gender is constructed and embedded in social, economic, and political contexts and institutions [12,22-24]; and (3) how culture and subcultures influence how men develop their masculinities and how they respond to health issues $[11,19,20,25]$. An intersectional approach is consistent with the focus and goals of men's health disparities research because it helps researchers consider how masculinities and social determinants of health combine and why they affect men's health and differences in health outcomes among men.

Understanding the relationship between masculinities and health requires a framework that accounts for both individual agency in making health choices and the social structures that shape health behaviors and health practices $[26,27]$. Masculinity is often signified by beliefs and behaviors that are practiced in everyday social and cultural patterns, practices, interactions and relations $[12,27]$. Because the social and cultural roles, expectations and norms of those who are biologically male are fundamentally shaped by race, ethnicity and gender [28], it is critical to examine how these socially-defined characteristics shape men's health and influence the relationship between masculinities and men's health [29].

\section{Toward an intersectional approach to men's health}

Figure 1 offers a framework for beginning to think beyond which social characteristics affect health to why those factors affect health. This framework builds from a model developed by Dr. Thomas LaVeist that helps researchers studying race and ethnicity to be more critical of the way they conceptualize, operationalize and utilize these terms in empirical research [30]. The current framework, however, begins with discussing race and gender as broad structural forces that fundamentally shape historical and current economic and social opportunities that map on to cultural factors, social practices and institutional policies that affect men's health $[7,31]$. These factors are not fundamentally more or less important than gender, but they are examples of social categories and 


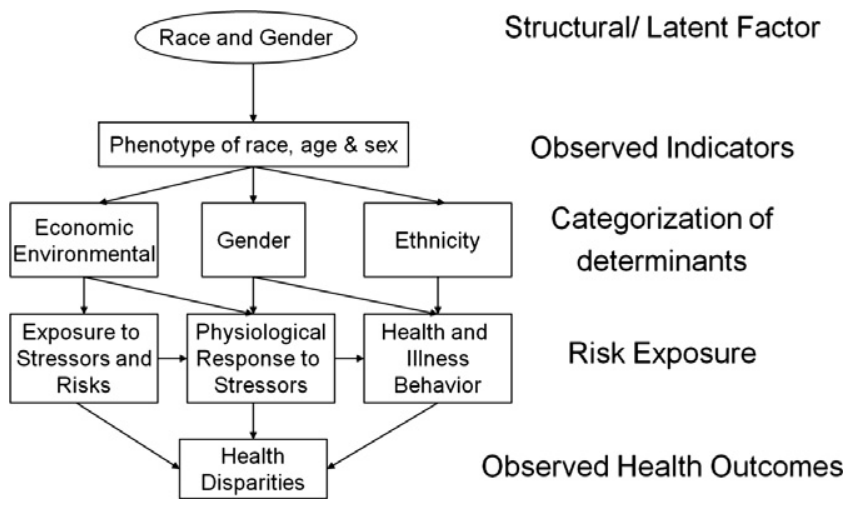

Figure 1 Intersectional approach to men's health disparities.

structures that are essential to creating a complete and unbiased examination of the role of gender in men's health because they shape individual opportunities and life chances through social and institutional practices [1]. These structural factors affect health through environmental and economic factors and ethnic or cultural pathways, which will be discussed in turn.

\section{Structural factors and observed indicators}

Structural factors, and the physical features that serve as indicators of them, trigger environmental, political and social determinants of health. The next section uses the case of African American men to illustrate how gender, race and age shape men's health, life chances and the observed indicators of these structural factors. Following this section is a discussion of two additional pathways that affect men's health: environmental/economic factors and ethnicity.

\section{Gender in men's health}

While it is not a static, trans-historical fact of nature or set of traits [32], prior notions of masculinity have often described and operationalized gender as acontextual, or as a relatively static, individually-based entity [27]. Measures of masculinity also have largely been operationalized and normed based on studies of young, White male college students [18]. Gendered processes - social relations and practices associated with biological sex - are the complex array of social relations and practices attached to sex that are rooted in biology and shaped by environment and experience $[33,34]$. Gender is both a structural characteristic that helps to define systems of social inequality and an individual level experience, and it is critical to explore how it is understood, experienced and practiced daily at both levels $[4,20]$.

Gendered cultural norms and expectations serve as stressors and psychological strains in men's social contexts and daily lives. Gendered social norms and pressures are often implicated in explanations of men's premature death due to unhealthy behaviors (e.g., reckless driving, alcohol and drug abuse) that may be used to cope with stress or reestablish that men embody a particular form of masculinity for oneself or for others $[2,12,13]$. Thus, gender affects men's health by triggering physiological and psychological responses that may lead to unconscious and conscious efforts to reduce the discomfort of experiencing stress [35]. Men will access culturally acceptable resources within their environments that they may have found "effective" in reducing stress before [35], they may have heard of or observed others using these strategies or they may simply be choosing what they see as the best possible resource. These culturally-appropriate behaviors are gendered, and may help explain the association between men's risky and unhealthy behaviors [13].

\section{Age in men's health}

Most of the ways we measure masculinity were developed and normed based on college student samples [29]; thus, utilizing these measures with other populations, particularly those who are older, may neglect, miss or misrepresent the relationship between gender and health. Because the fundamental meaning of masculinity and the salience of different aspects of masculinity change over the life course, it is critical to consider the relevance of current measures of masculinity for older 
men. Few existing measures of masculinity include constructs that are salient for the masculinities men perform in middle and older adulthood, particularly positive forms of masculinity [18]. Some of the masculinities men try to perform when they are younger tend to demonstrate their physical strength, sexual prowess and risk tolerance, but as men age they tend to also want to demonstrate more positive aspects of masculinity: being a responsible father, provider, husband, etc. $[17,36]$. For example, one study found that middle-aged African American men viewed their efforts to be good and active employees, family members, and community members as a barrier to engaging in physical activity [37].

Each phase of life can be distinguished, in part, by men's efforts to fulfill salient role performance goals [17,37]: educational and professional preparation in the pre-adult and early adult years; being a provider for himself and his family in the middle-adult years; and dignified aging as men move through older adulthood $[17,38]$. While these goals may not be universal, it remains critical to recognize that there are social and cultural pressures that men experience, and that these pressures and strains, which may be rooted in efforts to fulfill salient roles, change as men age. In addition to considering how role strains and stressors vary over time, age highlights the need to move beyond conceptualizing men's health in a cross-sectional fashion; men's health is the accumulation of experiences that happen over time [7]. In the next section, race will be discussed as a factor that also shapes men's health during key phases of life as well as over the lifecourse.

\section{Race in men's health}

Race and ethnicity are sociopolitical constructs, not anthropologically or scientifically-based categories, that are useful when the aims of research are to understand how stratification by race influences health [31]. What is described here as being associated with race may also apply to ethnic groups, but here these terms will be discussed separately. Differences in gene frequency between racial and ethnic groups have not been found to relate directly to health, but social and environmental factors have been empirically tied to racial disparities in health outcomes [39]. There have been problems with the way race has been used in health research, including a lack of consensus on the definition of race (domestically or internationally), poor measurement and changing definitions based on social and political considerations [40].

Critical masculinity scholars have emphasized the importance of locating men's health in the context of class-based, racialized masculinities [2,22,41-44]. Racially-linked factors shape the types of masculinities that men are able to embody because the environments where men live are influenced by the global, national and local meaning of race $[12,31,43]$. Members of certain racial and ethnic groups may face discrimination based on the social and cultural meaning ascribed to racial group membership $[1,45]$. Race is a particularly important determinant of health because it influences social class and economic position in society, not the other way around [46]. Both race and class are relational constructs rooted in the cultural definitions and meanings of these characteristics [47]. Economic position is often confounded with social class but these constructs can have different definitions and implications for health. For example, African American men may define themselves as middle class based less on economic position and more on values and social behavior [47]. Middle-class African Americans often are not much better off than their working-class White counterparts. Thus, it can be important for African American men to demonstrate their middle-class status through patterns of consumption and social behavior both to other African Americans as well as nonAfrican Americans in their social lives [47]. Understanding race and class in these ways has important implications for interpreting research that seeks to examine the subjective and objective aspects of race and class that serve as sources of stress in men's lives.

\section{Categorization of determinants and risk exposure}

\section{Ethnicity in men's health}

Ethnicity encompasses aspects of culture, social life and personal identity that sociallydefined groups tend to share [31]. Ethnic groups consist of people assumed to have common cultural and often similar physical traits that distinguish them from other ethnic groups, including primary language, nativity, history, traditions, values, and dietary habits [48]. Physical traits, however, are not presumed 
to distinguish ethnic groups nor assume superior or inferior groups [48]. Within national boundaries, ethnic groups are subcultures maintaining certain patterns of behaviors, beliefs and values that distinguish them from other cultural groups [49]. Ethnicity comprises two dimensions: the attributional dimension describes the unique sociocultural characteristics (e.g., culture, diet) of groups, while the relational dimension captures characteristics of the relationship between an ethnically defined group and the society in which it is situated [31]. In the context of men's health, distinguishing between race and ethnicity can help researchers disentangle health outcomes that may be due to environmental constraints and contexts that vary by race from the cultural traditions, beliefs, habits and practices that vary by ethnicity.

Environment, economics and men's health Race (and ethnicity) remains a useful marker of one's exposure to health-harming environments and substances, social disadvantage and health promoting resources [40]. Understanding the poor status of men's health and premature death includes considering how racialized and gendered social determinants of health shape men's lives and experiences, particularly through economic and environmental factors $[43,50,51]$. Poverty, poor educational opportunities, underemployment and unemployment, incarceration, and social and racial discrimination all vary by race and also influence the capacity of men to achieve and maintain good health [50-53]. The fact that some racial (and ethnic) groups are more likely to live in poverty, work in low-paying and dangerous occupations, reside in closer proximity to polluted environments, be exposed to toxic substances, experience threats and realities of crime, and live with cumulative worries about meeting basic needs highlights the importance of considering both gendered and non-gendered aspects of their environments, identities and experiences [51-54].

\section{The promise of intersectional approaches to men's health}

A few years ago, Lohan [55] argued that men's health needed a theory that linked the research on gender, masculinities and health to the literature on health disparities or health inequalities. In her paper, Lohan [55] articulated what factors should guide research examining the link between gender (masculinities) and health. This focus on intersectional approaches to men's health builds from Lohan's work and offers a framework that describes how and why the factors that shape health disparities and health inequalities also may affect men's health. These factors should not be considered independently as they combine to create new masculinities.

Intersectional approaches to men's health offer a way to examine why hegemonic masculinity does not have the same meaning and influence within and across all men's lives $[3,19,20]$. Intersectional approaches help to highlight how dynamic cultural factors shape the norms, expectations, stressors and practices in men's lives. An intersectional approach offers an important lens through which we may further explore how men determine strategies for recreating, reimaging and redefining masculinities. These strategies map onto structural factors such as race and gender; the social experience of being a biological male of a particular age, race and ethnicity; and environmental, economic and cultural (ethnic) factors that shape the life context, social experiences, psychological experiences and health practices. While often studied as characteristics of individuals, these factors reflect macro-level factors linked to disparate health practices and health inequalities $[1,3,18,56]$.

Intersectionality is not just a tool to facilitate understanding the experiences and practices of "minority", "marginalized", "subordinated" and poor men; the social structures and practices that give gender its meaning in men's lives involve hierarchy and inequality that affect all men. Future research using an intersectional approach to research on men's health should focus on four key factors: (1) commonalities across populations by exploring what individuals, institutions and cultures do, not what they are; (2) heterogeneity among populations, which can help identify the mechanisms and pathways that connect interlocking systems of privilege and oppression to socially-defined characteristics and men's health; (3) the salience of the socially-defined characteristic that is "primed" by a specific context or situation; and (4) explicating the pathways and mechanisms that connect individual cognitive and 
psychological factors and population-level social determinants of health [1]. This future research agenda could help to clarify four key areas of men's health research:(1) insights into the categories and practices that give sociallydefined characteristics meaning; (2) gendered factors that are a function of different contexts from gendered factors that result from different social roles; (3) the equivalence of the intersection of socially-defined characteristics for different populations; and (4) whether the intersection of socially-defined characteristics are additive, multiplicative or subtractive within and across populations. These directions highlight the need for researchers to include diverse groups in their studies that vary by socially-defined characteristics and power that emanates from social, economic, cultural and political factors [1].

\section{Conclusion}

Though men's health focuses on the extent to which social and cultural constructions shape men's health behaviors and health outcomes [57], we know relatively little about specific social-biological pathways through which gendered arrangements become embodied as differences in health among men or between males and females [34]. Intersectional approaches help to consider why and how the combination of socially-constructed identities and characteristics create new norms, expectations, masculinities and, ultimately, health outcomes. These approaches help researchers to be more thoughtful and deliberate in their study designs, quantitative and qualitative data analyses, and discussion of research findings and implications. Intersectional approaches also help to consider new and innovative ways that socially-defined characteristics relate to one another.

Intersectional approaches offer a way to consider why gender and masculinities are related to health and these approaches help to identify key pathways and stratification variables to guide future research. While explicating the role of gender in men's lives and health remains a primary focus of men's health research, it is critical to recognize that gender and other socially-defined categories depend on one another for meaning; failing to consider how gender intersects with other identities will lead to incomplete and biased explanations of men's health practices and outcomes [1].

\section{Acknowledgements}

This manuscript was supported in part by grants from the American Cancer Society (MRSGT-07-167-01-CPPB), the Michigan Center for Urban African American Aging Research (5P30AG015281), the Cancer Research Fund of the University of Michigan Comprehensive Cancer Center, and by the Center on Men's Health Disparities, University of Michigan, School of Public Health. Its contents are solely the responsibility of the author and do not necessarily represent the views of the funders or the University of Michigan.
References

[1] Cole ER. Intersectionality and research in psychology. Am Psychol 2009;64(3):170-80.

[2] Robertson S. Understanding Men and Health: Masculinities, Identity, and Well-being. Maidenhead: Open University Press; 2007.

[3] Griffith DM, Metzl JM, Gunter K. Considering intersections of race and gender in interventions that address U.S. men's health disparities. Public Health 2011;125(7):417-23.

[4] Weber L, Parra-Medina D. Intersectionality and women's health: charting a path to eliminating health disparities. In: Demos V, Segal MT, editors. Advances in Gender Research: Gender Perspectives on Health and Medicine. Amsterdam: Elsevier; 2003. p. 181-230.
[5] Bowleg L. When Black+ lesbian+ woman $\neq$ Black lesbian woman: the methodological challenges of qualitative and quantitative intersectionality research. Sex Roles 2008; 59:312-25.

[6] Mullings L, Schulz AJ. Intersectionality and health: an introduction. In: Schulz AJ, Mullings L, editors. Gender, Race, Class and Health: Intersectional Approaches. San Francisco: CA: Jossey-Bass; 2006.

[7] Warner DF, Brown TH. Understanding how race/ethnicity and gender define age-trajectories of disability: an intersectionality approach. Soc Sci Med 2011;72(8): 1236-48.
[8] McCall L. The complexity of intersectionality. Signs 2005;30(3):1771.

[9] Warner L. A best practices guide to intersectional approaches in psychological research. Sex Roles 2008;59:454-63.

[10] Purdie-Vaughns V, Eibach RP. Intersectional invisibility: the distinctive advantages and disadvantages of multiple subordinate-group identities. Sex Roles 2008;59(5-6):377-91.

[11] Bowleg L, Teti M, Massie JS, Patel A, Malebranche DJ, Tschann JM. 'What does it take to be a man? What is a real man?': ideologies of masculinity and HIV sexual risk among Black heterosexual men. Culture Health Sexuality 2011;13(5):545-59. 
[12] Courtenay W. A global perspective on the field of men's health: an editorial. Int J Mens Health 2002;1(1):1-13.

[13] Courtenay WH. Constructions of masculinity and their influence on men's well-being: a theory of gender and health. Soc Sci Med 2000;50(10):1385-401.

[14] Courtenay WH. Key determinants of the health and well-being of men and boys. Int J Mens Health 2003;2(1):1-27.

[15] Courtenay WH, Keeling RP. Men, gender, and health: toward an interdisciplinary approach. J Am Coll Health 2000;48(6): 243-6.

[16] Watkins DC, Walker RL, Griffith DM. A meta-study of black male mental health and well-being. J Black Psychol 2010;36(3): 303-30.

[17] Bowman PJ. Research perspectives on Black men: role strain and adaptation across the adult life cycle. In: Jones RL, editor. Black Adult Development and Aging. Berkeley, CA: Cobb \& Henry Publishers; 1989 . p. 117-50.

[18] Griffith DM, Gunter K, Watkins DC. Measuring masculinity in research on men of color: findings and future directions. Am J Public Health 2012; Mar 8 [Epub ahead of print].

[19] Coles T. Finding space in the field of masculinity. J Sociol 2008;44(3):233-48.

[20] Coles T. Negotiating the field of masculinity. Men Masc 2009;12(1):30-44.

[21] Connell RW. Masculinities. Oxford: Polity Press; 1995.

[22] Crawshaw P. Critical perspectives on the health of men: lessons from medical sociology. Crit Public Health 2009;19(3):279-85.

[23] Connell RW, Messerschmidt JW. Hegemonic masculinity: rethinking the concept. Gender Soc 2005;19(6):829-59.

[24] Hearn J. From hegemonic masculinity to the hegemony of men. Feminist Theory 2004;5(1):49-72.

[25] Malebranche DJ, Fields EL, Bryant LO, Harper SR. Masculine socialization and sexual risk behaviors among Black men who have sex with men. Men Masc 2009;12(1):90-112.

[26] Creighton G, Oliffe JL. Theorising masculinities and men's health: a brief history with a view to practice. Health Sociol Rev 2010;19(4):409-18.

[27] Smiler A. Thirty years after the discovery of gender: psychological concepts and measures of masculinity. Sex Roles 2004;50(1): $15-26$.

[28] Summers MA. Manliness and its Discontents: The Black Middle Class and the
Transformation of Masculinity, 19001930. Chapel Hill: University of North Carolina Press; 2004.

[29] Snow RC. Sex, gender, and vulnerability Global Public Health 2008;3(Suppl 1):58-74.

[30] LaVeist TA. Why we should continue to study race..but do a better job: an essay on race, racism and health. Ethn Dis 1996;6(1-2) 21-9.

[31] Ford CL, Harawa NT. A new conceptualization of ethnicity for social epidemiologic and health equity research. Soc Sci Med 2010; 71(2):251-8.

[32] Bederman G. Manliness and Civilization: A Cultural History of Gender and Race in the United States, 1880-1917. Chicago, IL: University of Chicago Press; 1996.

[33] Evans J, Frank B, Oliffe JL, Gregory D. Health, Illness, Men and Masculinities (HIMM): a theoretical framework for understanding men and their health. J Mens Health 2011;8(1): 7-15.

[34] Springer KW, Mager Stellman J, JordanYoung RM. Beyond a catalogue of differences: a theoretical frame and good practice guidelines for researching sex/ gender in human health. Soc Sci Med 2011; June 15. [Epub ahead of print].

[35] Jackson JS, Knight KM. Race and selfregulatory health behaviors: the role of the stress response and the HPA axis. In: Schaie KW, Carstensten LL, editors. Social Structure, Aging and Self-regulation in the Elderly. New York: Springer; 2006. p. 189240.

[36] Hammond WP, Mattis JS. Being a man about it: manhood meaning among African American men. Psychol Men Masc 2005;6(2):11426.

[37] Griffith DM, Gunter K, Allen JO. Male gender role strain as a barrier to African American men's physical activity. Health Educ Behav 2011;38(5):482-91.

[38] Erickson EH. Identity and the Life Cycle. New York: Norton; 1980.

[39] Sankar P, Cho MK, Condit CM, Hunt LM, Koenig B, Marshall P, et al. Genetic research and health disparities. JAMA 2004;291(24): 2985-9.

[40] LaVeist TA. On the study of race, racism, and health: a shift from description to explanation. Int J Health Serv 2000;30(1):217-9.

[41] Connell RW. The Men and the Boys. Sydney: Allen \& Unwin Australia; 2000.

[42] Schofield T, Connell R, Walker L, Wood J, Butland D. Understanding men's health and illness: a gender-relations approach to policy, research, and practice. J Am College Health 2000;486:247-56.
[43] Pease B. Racialised masculinities and the health of immigrant and refugee men. In: Broom A, Tovey P, editors. Men's Health: Body, Identity and Context. Chichester, USA: John Wiley and Sons; 2009p. 182-201.

[44] Riska E. Masculinity and Men's Health: Coronary Heart Disease in Medical Public Discourse. Oxford: Rowman and Littlefield; 2006.

[45] Griffith DM, Johnson J, Ellis KR, Schulz AJ. Cultural context and a critical approach to eliminating health disparities. Ethn Dis 2010;20(1):71-6.

[46] Kawachi I, Daniels N, Robinson DE. Health Disparities By Race And Class: Why Both Matter. Health Aff 2005;24(2):343-52.

[47] Cole ER, Omari SR. Race, class and the dilemmas of upward mobility for African Americans. J Soc Issues 2003;59(4):785-802.

[48] Smedley A, Smedley BD. Race as biology is fiction, racism as a social problem is real: anthropological and historical perspectives on the social construction of race. Am Psychol 2005;60(1):16-26.

[49] Marger M. Immigrant business as a form of ethnic economic adaptation: the North American context. In: Isajiw WW, editor. Multiculturalism in North America and Europe: Comparative Perspectives on Interethnic Relations and Social Incorporation. Toronto: Canadian Scholars' Press; 1997. p. 261-71.

[50] Treadwell H, Braithwaite K. Men's health: a myth or a possibility? J Mens Health Gend 2005;2(3):382-6.

[51] Young AMW. Poverty and men's health: global implications for policy and practice. J Mens Health 2009;6(3):272 [Abstract].

[52] Xanthos C, Treadwell HM, Holden KB. Social determinants of health among African American men. J Mens Health 2010;7(1):11-9.

[53] Young AMW, Meryn S, Treadwell HM. Poverty and men's health. J Mens Health 2008;5(3):184-8.

[54] Sabo D. The study of masculinities and men's health: an overview. In: Kimmel M, Hearn J, Connell RW, editors. Handbook of Studies on Men and Masculinities. Thousand Oaks: Sage Publications; 2005. p. 326-52.

[55] Lohan M. How might we understand men's health better? Integrating explanations from critical studies on men and inequalities in health Soc Sci Med 2007;65(3):493-504.

[56] Jackson PB. Health inequalities among minority populations. J Gerontol Ser B Psychol Sci Soc Sci 2005;60(Special Issue 2):S63-7.

[57] Lee C, Owens RG. The Psychology of Men's Health. Philadelphia, PA: Open University Press; 2002 